ESTUDOS REEP

\title{
A pesquisa em políticas públicas de educação numa perspectiva histórica
}

André Luiz Paulilo

\section{Resumo}

Pretende apreender como a história das políticas educacionais vem sendo apropriada pela área de história da educação enquanto campo de investigação. Para tanto, analisa as contribuições da sociologia política neste campo. Discorre, também, sobre o levantamento, organização e ampliação da massa documental a ser utilizada na análise das políticas educacionais. Chama a atenção ainda para o concurso da noção de cultura escolar nas investigações que empregam os arcabouços aqui discutidos. Ao final, aponta alguns dos desafios que precisam ser levados em conta no estudo histórico e para o aprofundamento teórico-metodológico das pesquisas em história das políticas educacionais.

Palavras-chave: políticas públicas; políticas educacionais; história da educação. 


\section{Abstract \\ Research on public education policy in a historical perspective}

This article aims to apprehend how the history of education policies has been taken by the area of history of education as a field of research. It analyzes the contributions of political sociology in the field. It also approaches the process of collecting, organizing and expanding a mass of documents to be used in the analysis of educational policies. Also, it draws attention to the notion of school culture in the investigations that employ the framework discussed here. In the end, it points out some of the challenges that must be taken into account in the historical study and the theoretical and methodological deepening of research on the history of education policies.

Keywords: public policies; educational policies; history of education.

Este artigo tem o propósito de discutir as possibilidades de pesquisa das políticas educacionais na perspectiva histórica. Seu principal objetivo é explorar as relações entre teoria social e história nos debates acerca do estudo e do exame das políticas públicas de educação. A eventual utilidade do empreendimento advém da tentativa de combinar modelos e métodos comuns a mais de uma disciplina. De fato, em meio às teorias e tipologias das ciências sociais, o que se pretende aqui é destacar a relevância da história da educação na configuração de modelos explicativos capazes de fundamentar análises sociais acerca das políticas educacionais. Por outro lado, trata-se de mostrar como o uso de conceitos forjados na sociologia e nas ciências políticas auxilia na compreensão das mudanças ocorridas com o passar do tempo nas formas de escolarização da sociedade.

Do ponto de vista teórico-metodológico, é um tanto comum a avaliação de que a sociologia pauta o principal da discussão em torno do estudo e da análise das políticas educacionais, enfatizando as generalizações sobre sua estruturação e desenvolvimento (cf. Cuin, Gresle, 1994, p. 261-262). A historiografia da educação sequer tem apresentado estudos sob o rótulo de história das políticas educacionais. Segundo Sanfelice (2004, p. 103), isso ocorre porque o tratamento histórico das políticas educacionais não é outra coisa senão história política. Ainda que assim, conforme atesta a renovação da historiografia política das últimas três décadas, a história das políticas educacionais seja repleta de possibilidades de interlocução com outras ciências sociais. Nesse sentido, conforme Julliard (1976, p. 190) colocou para o caso da história política, também a abordagem histórica da ação do Estado sobre a educação não será forçosamente factual, "desde que se retenha do poder uma noção muito mais ampla, na qual o 
Estado, essa instituição das instituições, seria apenas um caso particular, um caso limite mesmo". Contudo, a sociologia já reúne pesquisas em políticas educacionais que têm reforçado o seu contato com a história. No modo como Popkewitz (1997, p. 27) pratica a sociologia política das reformas educacionais, "limitar a curiosidade somente ao presente e ao funcional é anti-intelectual e, até mesmo, anticientífico." De fato, tanto quanto a pesquisa em história das políticas educacionais, a dimensão histórica dos estudos de sociologia da educação expressa e estimula um esforço comum entre historiadores e sociólogos no sentido de desenvolver tipologias analíticas e modelos explicativos.

Sob esse ponto de vista, a intenção deste artigo é explorar algumas áreas de contato. Suas seções tratam, sucessivamente, das alternativas entre a macrossociologia e a história política, das contribuições da sociologia política, do conceito de ciclo de políticas, das fontes de pesquisa, da cultura escolar como categoria de análise e da abordagem das instituições escolares. Por fim, o tema das políticas educacionais é analisado enquanto questão historiográfica.

\section{Alternativas entre a macrossociologia e a história política}

Os estudos de Stephen Ball e de Thomas Popkewitz acerca das mudanças educacionais na Grã-Bretanha e nos Estados Unidos advertem a respeito do caráter histórico e relacional das estruturas de escolarização, sobretudo, lidam com um referencial teórico que permite relacionar as práticas e os discursos sobre os quais as atividades diárias e o pensamento individual são estabelecidos num momento de reforma do ensino. Ambos os autores se utilizam da chamada análise pós-estruturalista para investigar o papel construtivo da linguagem na implantação das reformas da educação. Basicamente, tanto Ball quanto Popkewitz compreendem a mudança e o poder como aspectos de relações definidas dentro de um espaço social. Assim, propuseram análises em que a diversidade das práticas produzidas por padrões emergentes de discurso é reconhecida e pensada enquanto resposta a um sistema estável de disposições inculcadas por socialização nos indivíduos. Os resultados que Ball e Popkewitz obtiveram com uma abordagem desse tipo mostram-se representativos das tentativas de analisar as políticas ou reformas educacionais como práticas sociais.

Ainda que para Thomas Popkewitz (1997, p. 29) os conceitos de Estado e poder sejam categorias estruturais no estudo da mudança na escola contemporânea, sua preocupação com os padrões epistemológicos e institucionais das reformas educativas concede amplo lugar à história na análise. Na sociologia política que Popkewitz pratica, o enfoque histórico é reivindicado para a organização de casos e o reconhecimento de mudanças naquilo que parecia ser contínuo (p. 37). Nessa perspectiva, descrevem-se vários padrões de relações entrelaçadas através do tempo, que são elementos para o estudo da mudança dos processos de escolarização. Sobretudo, é reconhecendo, à maneira de Foucault, as 
estruturas sociais como objetos historicamente formados que Popkewitz analisa as reformas educacionais como uma interseção de saberes com o poder e com as práticas situadas historicamente (p. 38-39). Não que ele realize uma arqueologia ou uma genealogia do conhecimento no sentido em que Foucault o fez, mas concentrando-se nas relações de poder entre instituições de saber, como são as agências governamentais, os grupos universitários, as fundações filantrópicas e as "escolas" de pesquisa, Popkewitz procurou compreender a construção histórica das epistemologias que considera básicas para a escolarização contemporânea e as formas nas quais a reforma educacional se constitui (p. 39).

Já na abordagem das políticas educacionais, apresentada nas pesquisas de Stephen Ball, a perspectiva histórica não tem lugar. Entretanto, em trabalhos como Reforming education and changing schools: case studies in policy sociology e Education reform: a critical and post-structural approach, Ball e colaboradores desenvolveram uma tipologia analítica para o estudo das políticas públicas de educação que considero relevante também para os estudos em história. Fundamentalmente, o modelo do ciclo de políticas (policy cycle) pode ser muito promissor para uma compreensão histórica das políticas educacionais. Ao propô-lo, Ball formaliza a análise de contextos para um ciclo contínuo de políticas públicas de educação. De acordo com Mainardes (2006, p. 50), são contextos inter-relacionados, sem uma dimensão temporal ou sequencial e que não configuram etapas lineares. Inicialmente, tratava-se do contexto de influência, de produção de texto e da prática. Posteriormente, Ball (1994) acrescentou ainda dois contextos ao referencial inicial, o dos resultados e o das estratégias políticas. Ainda que não seja o caso de aplicar tipologias constituídas no âmbito da abordagem do ciclo de políticas, a familiaridade com esse modelo explicativo pode auxiliar a análise histórica das políticas públicas de educação. Sobretudo, a sociologia política de Ball (1994; Bowe, Ball, Gold, 1992) teoriza sobre a totalidade de um processo de planejamento e implantação, cuja estruturação a história tem detalhado e descrito segundo recortes de interesse.

$\mathrm{O}$ atual interesse historiográfico pela materialidade dos processos de produção, circulação e apropriação culturais mostra que tanto as estruturas sociais quanto os acontecimentos políticos devem ser vistos como culturalmente constituídos ou construídos (cf. Burke, 1991, p. 98; Nunes, Carvalho, 1993, p. 41). Nesse sentido, a primeira coisa a constatar é que, numa perspectiva histórica desse tipo, a política educacional também se define como uma prática social. Não obstante, esse objeto de estudo mostra-se compreensível a partir da materialidade dos seus dispositivos e das lutas de representação (Chartier, 1990), que fomentam tanto na macroestrutura do Estado quanto na micropolítica das disputas cotidianas. A consequência, e esse é o segundo traço a destacar, é que o estudo da política educacional no âmbito dessa história se realiza a partir de uma crítica documental, capaz de constituir como representação de um real os vestígios de uma prática (cf. Chartier, 1990). Em relação à sociologia política de Ball e Popkewitz, parte da especificidade do método 
histórico está na construção da sua "base de dados". Perante a pesquisa empírica sistemática, sobre a qual se configura, por exemplo, a abordagem do ciclo de políticas, a história compreenderá, de acordo com Sanfelice (2004, p. 99-100), as políticas públicas de educação a partir das fontes que traduzem a sua geração e lhes dão materialidade.

Em razão de tudo isso, e esse é o último aspecto do interesse historiográfico da educação pela história cultural que considerarei aqui, emergiram estudos voltados para o interior das instituições de ensino. A rejeição das interpretações que na esteira de Bourdieu e Passeron (1975) pretendiam ver na escola apenas o lugar de reprodução social é um elemento presente atualmente nas investigações acerca da cultura escolar. Enquanto problemática de pesquisa, a noção de cultura escolar tem propiciado conceber a escola como um produto de práticas que tanto podem "escolarizar" saberes constituídos fora dos estabelecimentos educativos quanto serem socialmente apropriadas em âmbitos não escolares. Essa categoria de análise contribuiu para a compreensão das práticas escolares enquanto dispositivos de transformação material de outras práticas culturais e de seus produtos.

Nessa perspectiva, também é relevante considerar as políticas de administração das instituições escolares, problematizando-se as estratégias de imposição de modelos culturais via escolarização. Todavia, o uso da noção de cultura escolar como categoria de análise num estudo das políticas públicas permite pensar a multiplicidade dos projetos e das representações instituídas ou apropriadas por docentes e administradores e, assim, investigar os padrões dentro dos quais ocorre a reforma do ensino como sendo plural e instável (cf. Viñao Frago, 2001). Por outro lado, as políticas educacionais operam sobre invariantes estruturais de organização das instituições de ensino que as noções de cultura escolar, forma escolar e gramática da escola percebem. São categorias instrumentais para uma reflexão acerca dos discursos que se articulam nas práticas escolares, dos seus dispositivos, das suas estratégias narrativas, das suas articulações retóricas e dos seus modos de enunciação. Conforme mostram os estudos de Vidal (2005, [s.d.]), a noção de cultura escolar não tem um sentido unívoco. Segundo suas conclusões de pesquisa, os conceitos de cultura escolar, forma escolar e gramática da escola oferecem um repertório analítico, que possibilita discorrer sobre as invariantes estruturais da escola, mas também indagar-se acerca das transformações (Vidal, 2005, p. 45). Insistindo no entendimento das práticas escolares e dos seus aspectos cotidianos, nas múltiplas apropriações do espaço e do tempo escolar, auxiliam a percepção dos resultados que as políticas educacionais produzem no interior da escola.

Do modo como vêm sendo praticadas, a sociologia política das reformas escolares e a história cultural da escola abrem perspectivas de estudo para as políticas públicas de educação que vão além das questões postas pela macrossociologia e pela história política. Sobretudo, consolidam um veio de aproximação entre as análises macropolíticas, especialmente preocupadas com a ação conjuntural do governo, e os estudos 
voltados para o interior das instituições de ensino. Sob esse aspecto, compreender historicamente as políticas educacionais significa, mais que estudar os atos do poder público ou o pensamento de líderes políticos, explorar as articulações entre os lugares de poder constituídos, as ações dos indivíduos no momento de organizar o uso dos objetos culturais em circulação nas escolas e o "campo de forças" (Popkewitz, 1997, p. 34) que impõe determinadas relações àqueles que nele penetram. O objetivo da pesquisa histórica é, então, estabelecer um certo número de relações entre o conjunto de documentos que concernem aos serviços públicos de educação de tal data a tal outra. Não obstante o desafio historiográfico, a construção conceitual das categorias de análise mostra-se central na compreensão das políticas educacionais não só enquanto ação de governo, mas também como uma prática social.

\section{Nos âmbitos de uma sociologia política da reforma educativa}

A ênfase que Popkewitz procura dar à história, quando conceitua a noção de estrutura como dinâmica e instável, contribui, ao menos de dois modos, com os estudos da reforma educativa. Primeiro, mostra que a história da reforma escolar não é somente a da transformação das ideias a respeito das práticas organizacionais, mas também a dos valores e interesses não reconhecidos que estão inseridos nas práticas de escolarização em curso. Nesse sentido, por perderem de vista a complexidade empírica das práticas sociais da escola e as formas em que a mudança é produzida, são rejeitados os conceitos definidos globalmente sobre estrutura. De outro modo, Popkewitz pratica uma sociologia política que é capaz de compartilhar percepções de temporalidade e ruptura com a história. Suas preocupações com os tipos de racionalidade que vêm a prevalecer na definição da escolarização ao longo do tempo advertem que as políticas públicas de educação também são parte da história social da escola (cf. Popkewitz, 1997, p. 234).

A primeira contribuição parece, então, ter a ver com um propósito conceitual. Para Popkewitz (1997, p. 23), o método histórico facilita uma análise da forma como os fatos atuais se relacionam com outros fatos, formados por padrões do passado e destes desvinculados. Em uma perspectiva desse tipo, são significativas para o estudo as categorias e as regras atribuídas ao conhecimento trazido para a escola e as formas por meio das quais as novas regras do currículo expressam novas relações de poder. Assim, pareceu pouco importante o fato de o novo currículo de ciência e matemática não ter sido utilizado quando foi proposto nos anos 60 nos Estados Unidos. No entanto, a abordagem de Popkewitz mostra que o movimento em direção à padronização e ao controle dos resultados escolares nos anos 80 tomou as distinções e as categorias dos anos 60 (p. 37). O enfoque histórico dessa manobra possibilita observar um acontecimento repleto de consequências. É particularmente sobre fatos desse tipo que Popkewitz questiona a reconstituição do sistema burocrático do ensino estadunidense e a formação de um discurso político sobre a educação (p. 116-117, 121-123, 136-137). 
Uma segunda contribuição diz respeito ao estudo da mudança educacional. Popkewitz esboça uma abordagem das formas em que a mudança é produzida na escola. Sensível aos aspectos sociológicos da noção de mudança levantados por Bourdieu, combina uma análise do espaço social dentro das instituições, e entre elas, com uma investigação do modo como esse espaço se une às epistemologias da escolarização e aos seus programas de reforma. Como Bourdieu, Popkewitz (1997, p. 34) usa a noção de espaço social para analisar a forma pela qual os diversos sujeitos históricos se relacionam por meio de diferentes formas de poder, como o poder cultural, social ou econômico. No entanto, é em torno dos estudos de Foucault que define o seu principal enfoque metodológico. Segundo Popkewitz, a relação que Foucault estabelece entre o poder e o conhecimento permite, principalmente, estudar as reformas educacionais como um aspecto institucional historicamente formado (p. 38). Sob esse modelo, a abordagem se detém nas formas como o conhecimento promove certas verdades, à medida que elas estão inseridas nos problemas, questões e respostas que asseguram e reforçam a vida social. Em relação às perspectivas de investigação abertas por Bourdieu e Foucault, Popkewitz enfatiza as regras e os constrangimentos sociais e as relações de poder por meio das quais se desenvolve o conhecimento acerca da escolarização. Naquilo que ele denomina epistemologia social, define-se o propósito que orienta a sua abordagem da mudança educacional:

Tenho usado a expressão epistemologia social referindo-me à linha de análise que orienta este estudo: a relação do conhecimento, instituições e poder. Uso epistemologia como um conceito histórico, social e pragmático. Ao contrário da maioria da filosofia americana, procuro analisar a inter-relação da mente com as condições materiais e não considerá-las como dualistas. Além disso, tenho procurado postular uma teoria do conhecimento como uma teoria histórica da sociedade e da individualidade. Filosoficamente, os estudos epistemológicos americanos os têm separado, dando prioridade ao conhecimento como a fundamentação de toda a ciência e ética. Finalmente, define a epistemologia como uma análise das relações entre a forma e o estilo de raciocínio e várias configurações e trajetórias históricas. Com a filosofia pragmática, afirmo que não há base comum onde possamos colocar um verdadeiro consenso ou um modelo neutro permanente, segundo o qual seja possível avaliar um argumento racional. Não há esquemas universais de raciocínio e racionalidade, mas somente epistemologias socialmente construídas que representam e incorporam relações sociais. (Popkewitz, 1997, p. 39).

Não obstante o âmbito epistemológico da mudança educacional, Popkewitz opera a análise das práticas que são parte dinâmica da regulamentação social e servem como marcos da escolarização por meio das noções de mentalidade e de poder. Sobretudo no modo como aparecem nos seus textos de 1992, 1997 e 1999, trata-se de categorias utilizadas para tornar as relações estruturadas entre instituições uma problemática política. Segundo Popkewitz, as mudanças nos padrões de percepção dessas relações estruturadas pareceram tão significativas ao estudo das reformas educativas quanto as práticas de Estado. Nesse sentido, o tipo 
de problema que a abordagem da mentalidade ajuda a pensar é o dos intercâmbios comuns entre instituições semiautonômas. Na escolarização, Popkewitz (1997, p. 35-36) entende que "a formação de professores se inter-relaciona com os padrões escolares de ensino e administração, como ele é levado para a educação superior e o trabalho da filantropia e da universidade". Há nisso uma série de aspectos relacionados à mudança que Popkewitz explora sistematicamente. Principalmente, identifica as relações que a visão de profissionalização do currículo, como parte de padrões de tempo de longa duração da vida material e cultural estadunidense, estabelece entre as reformas específicas dos anos 80 e as dos anos 60 do século passado.

Há, nesse tipo de análise, uma compreensão explícita de que a história do desenvolvimento dos modelos pedagógicos de formação escolar "não é uma história cronológica dos avanços progressivos ou de uma progressão seriada" (Popkewitz, 1997, p. 36). À maneira de Braudel, Popkewitz argumenta que a história das práticas sociais "passa com mil ritmos diferentes, suave e lento, que não mostra quase nenhuma relação com o ritmo do dia a dia de uma história cronológica ou tradicional" (p. 36). Considerada como estrutura do conhecimento nessa perspectiva de abordagem, a noção de mentalidade é vista como o resultado da interação de diferentes períodos históricos. Segundo essa compreensão, a mudança será encontrada na mistura de relações estruturais que ocorreram com ritmos diferentes dentro das diversas instituições (cf. Popkewitz, 1997, p. 37).

Em outra ordem de preocupações, Popkewitz utiliza-se da noção de poder, proposta por Foucault, para refletir a propósito das relações estruturadas que existem entre a sociedade civil e a autoridade pública. Em parte, há nisso um investimento teórico na compreensão das tecnologias de controle e supervisão da escola pelo Estado. Sobretudo nessa perspectiva, Popkewitz apresenta uma definição de Estado diferente do conceito weberiano de poder legal-administrativo quando dirige sua atenção para os dispositivos do governo, dos quais a escola é um elemento importante. Sua compreensão desses dispositivos se faz mediante a abordagem das técnicas impostas à escola para regular o indivíduo de uma forma que se inter-relacionavam com as múltiplas demandas da nova economia, da cultura e do Estado em expansão nos Estados Unidos. Popkewitz (1997, p. 50) assume que nessa noção de poder certos interesses e personagens sociais surgem à análise para dar direção às práticas de governo do momento, pois há uma preocupação com quem dita as regras e como essas regras são postas em ação. Porém, o poder que subjaz aos processos de governo possui um outro sentido. Sempre de acordo com a noção de poder de Foucault, Popkewitz adverte que há uma organização social e epistemológica das escolas na produção de uma disciplina moral, cultural e social da população. Assim, a ideia de que o Estado assume um lugar determinante na formação da sociedade civil e que a regulação social do individual é fundamental para a produção da vontade, do desejo e dos valores na sociedade confere um segundo sentido para a noção de poder. Numa perspectiva assim, Popkewitz mostra que o enfoque da análise incide 
sobre a forma como os indivíduos são constituídos e como os mecanismos que censuram o self, isto é, a escolha de um conjunto de práticas em detrimento de suas alternativas, compõem estratégias de produção de identidade. Ambos os sentidos que a noção de poder assume na reflexão de Popkewitz trazem consigo a ideia de que as políticas de escolarização e de currículo advêm de um tipo de gestão comprometido em estabelecer vínculos entre o governo do Estado e do individual. Ocorre, então, que, sob uma abordagem desse tipo, a reforma da escola pode ser vista como parte da história das relações que vinculam os indivíduos aos problemas de governo (cf. Popkewitz, 1997, p. 51).

A discussão que Popkewitz faz a respeito da epistemologia e da instituição das reformas educacionais traz consigo uma acentuada perspectiva histórica para a análise das relações entre saberes, instituições e poder nas políticas de escolarização em massa. Ela encoraja a investigação das práticas institucionais e dos regimes de verdade à medida que se modificam com o passar do tempo. Tendo em vista as relações entre epistemologia e contextos histórico e social, Popkewitz (1997, p. 240-241) adverte que a administração política da educação é historicamente estruturada e interage por meio de múltiplas relações sociais. Nesse sentido, suas contribuições teóricas quanto ao estudo da mudança em educação são principalmente efetivas para uma história das relações estruturais onde a escolarização ocorre. Nos estudos de Popkewitz $(1994,1997)$ a respeito das reformas educativas e das suas políticas de poder, as noções de estrutura, mentalidade e longa duração desvelam um foco explícito e consciencioso sobre as possíveis conexões entre categorias históricas de análise e modelos explicativos associados às ciências sociais.

\section{Acerca da abordagem do ciclo de políticas em educação}

A ideia da existência de um "ciclo de política" (policy cycle) nas reformas educacionais é o resultado de uma reflexão de Stephen Ball (1994) e colaboradores (Bowe, Ball, Gold, 1992) sobre a trajetória dos programas de reorganização escolar, desde a formulação até a implementação. A expressão faz parte de uma teoria que não apresenta uma dimensão temporal ou sequencial para as trajetórias das políticas públicas e, tampouco, as organiza de um modo linear. Segundo Mainardes (2006, p. 50), o foco da análise incide sobre a formação do discurso da política e a interpretação ativa que os profissionais atuantes no contexto da prática fazem para relacionar os textos da política à prática. O que se propõe, então, com a abordagem do ciclo de políticas (policy cycle approach), é uma investigação dos processos de resistência, das acomodações e dos subterfúgios dentro e entre os contextos de formulação, implementação e uso de um programa ou de uma política de reforma educacional.

Para o modelo analítico proposto por Ball, as noções de influência, produção de texto, prática, resultado e estratégia são centrais. Principalmente por meio delas, Ball (1994; Bowe, Ball, Gold, 1992) 
classificou aquilo que entendeu serem as facetas da análise das políticas de educação.

Inicialmente, o âmbito no qual as políticas públicas são planejadas e os discursos políticos construídos definem o uso que Ball (1994; Bowe, Ball, Gold, 1992) faz da noção de influência. Assim, é significativo que a formulação das políticas seja compreendida tendo em conta as instâncias sociais geradoras de ideias e os conflitos e disputas entre elas. Nesse sentido, os grupos que disputam para influenciar a definição das finalidades sociais da educação constituem uma primeira instância de análise. Particularmente nesse caso, importa à abordagem compreender as redes sociais dentro e em torno de partidos políticos, do governo e do processo legislativo. Também é por meio da noção de influência que Bowe, Ball e Gold (1992) focaram os processos de legitimação e formulação do discurso básico da política. Sob esse aspecto, busca-se compreender as arenas da ação pública, como os meios de comunicação social, as comissões e os grupos representativos e os demais lugares de articulação de influência. Já as influências globais e internacionais são incluídas no esquema geral de formulação das políticas públicas a partir de estudos acerca da circulação internacional de ideias (Popkewitz, 1984), do processo de empréstimo de políticas (Halpin, Troyna, apud Ball, 1998) e dos grupos que vendem suas soluções no mercado político e acadêmico (cf. Mainardes, 2006, p. 51). Outra face desse âmbito de influências são as soluções recomendadas por agências multilaterais, como o Banco Mundial, a Organização para a Cooperação e o Desenvolvimento Econômico (OCDE), a Organização das Nações Unidas para a Educação, a Ciência e a Cultura (Unesco) e o Fundo Monetário Internacional (FMI). Essas agências exercem influências sobre a criação de políticas, ainda que a promoção das suas ideias ou a implantação dos seus programas não se dê por mera transposição ou transferência, como adverte a literatura especializada. Em casos desse tipo, afirma-se que as políticas são recontextualizadas no interior de contextos nacionais específicos (Ball, 1998, 2001; Robertson, 1995; Edwards et al., 2004).

Na abordagem do ciclo de políticas, a noção de produção de texto mantém, por um lado, estreita relação com a teoria literária e, por outro, com a materialidade dos textos políticos. Nesse caso, consideram-se textos políticos as várias formas de apresentação e disseminação das diretrizes das políticas públicas, desde a legislação e os comentários formais e informais acerca deles até os pronunciamentos e vídeos. Como consideram Bowe, Ball e Gold (1992, p. 22), as políticas são intervenções textuais que, contudo, possuem limitações materiais e possibilidades. Tendo em vista tratar dessas limitações, Ball (1993) propôs pensar a política como "texto" e como "discurso". Ele entende, no primeiro caso, que, enquanto texto, as políticas constituem representações que são codificadas de maneiras complexas, tendo, por isso, uma pluralidade de leituras em razão da pluralidade de leitores. Por outro lado, Ball (1993) explica que, como discurso, as políticas incorporam significados e utilizam proposições e palavras por meio das quais são construídas certas possibilidades de pensamento. Assim, os discursos das políticas configuram-se como o 
resultado de múltiplas influências e sua formulação envolve intenções e negociações dentro do Estado. De acordo com Mainardes (2006, p. 54), enquanto a "política como discurso" enfatiza os limites impostos pelo próprio discurso, a "política como texto" enfatiza o controle que está nas mãos dos leitores. A distinção é complementar, mas, sobretudo, decisiva para estabelecer os limites entre o que é permitido pensar, e tem o efeito de legitimar discursos, e aquilo com que o leitor se envolve enquanto intérprete criativo.

A noção de prática, com a qual trabalharam Ball e seus colaboradores, circunscreve o contexto em que a política está mais sujeita à interpretação e recriação. A ideia de que as políticas não são simplesmente implantadas como foram propostas torna explícita a existência de práticas de apropriação e/ou resistência que produzem efeitos que podem representar mudanças e transformações significativas na política original. No nível da prática, a abordagem do ciclo de políticas assume que os profissionais que atuam nas escolas exercem um papel ativo no processo de interpretação e reinterpretação das políticas. Em razão disso, considera-se que aquilo que professores e demais agentes escolares acreditam e pensam tem implicações para o processo de implementação das políticas educacionais (cf. Mainardes, 2006, p. 53).

A ideia de efeito ou resultado como categoria de análise foi proposta por Ball (1994) para considerar questões de justiça, igualdade e liberdade individual. Em torno dessas noções, as políticas deveriam ser analisadas em relação ao seu impacto e a sua interação com as desigualdades existentes. Nesse âmbito, Ball sugere que a análise de certa política pública deve envolver o exame das várias facetas e dimensões de uma política, suas implicações e interface com outras políticas setoriais e com o conjunto delas. Pode-se destacar que o impacto das políticas sobre grupos específicos e localizados, tais como os de gênero, raça, classe, necessidades especiais, entre outros, pode ser considerado neste momento da discussão. Como lembra Mainardes (2006, p. 57), a ideia de que há efeitos de primeira e de segunda ordem evidencia a preocupação de Ball com as questões de justiça social, padrões de acesso e oportunidades sociais. De primeira ordem, então, seriam os efeitos referentes a mudanças na prática ou na estrutura, evidentes em lugares específicos ou no sistema como um todo. Os efeitos de segunda ordem dizem respeito ao impacto dessas mudanças nos padrões de acesso social, oportunidade e justiça social. Assim, Ball (1994, 1998, 2001) vem consolidando esforços no sentido de identificar as variáveis que causam impactos sobre os resultados das políticas públicas. Rejeitando o pressuposto de que sua formulação e implementação são processos exclusivamente racionais e lineares, desvinculados dos processos políticos, a abordagem do ciclo de políticas enfatiza o melhor entendimento dos resultados (cf. Souza, 2003, p. 17).

Por fim, a noção de estratégia envolve a identificação do conjunto de atividades sociais e políticas necessárias para tratar com as desigualdades criadas ou reproduzidas pela política investigada. No interior da abordagem do ciclo de políticas, este é um elemento específico da pesquisa 
social crítica. A principal questão que o estudo da estratégia política coloca é a da reflexão conjuntural sobre as desigualdades sociais provocadas ou reproduzidas pela política ou pelo programa de reforma educacional. Nesse âmbito, o aspecto essencial da análise é a compreensão crítica das ações e dos compromissos políticos das intervenções governamentais planejadas nos serviços de educação.

Numa perspectiva histórica de análise das políticas educacionais, a noção de ciclo de políticas qualifica o estudo da organização geral da educação em suas relações com o Estado, autoridades oficiais e professores em dois aspectos principais.

Primeiro, há no enfoque que Bowe, Ball e Gold (1992) oferecem das políticas educacionais uma possibilidade investigativa atenta às conexões entre os interesses dos atores, a produção de textos legais e políticos e os contextos da prática. Sobretudo nos termos como colocam a questão, a ideia de abordagem do ciclo de políticas permite deslindar as relações entre os lugares de articulação da influência de grupos representativos, os textos oficiais e os políticos, os comentários formais ou informais sobre os textos oficiais e os processos de interpretação e apropriação das diretrizes da reforma pelos professores. Cada uma dessas instâncias é tratada como um contexto diferente de formulação e implantação das reformas educacionais ao passo que constituem âmbitos ou arenas de delineamento de conflitos e disparidades entre discursos, grupos e quadros funcionais. Essa abordagem oferece instrumentos para se circunscrever os processos de institucionalização dos serviços de educação num ciclo de políticas. Nesse sentido, a contribuição de Bowe, Ball e Gold (1992) para uma reflexão acerca dos resultados das políticas públicas de educação acena com instrumentos para a crítica dos regimes de verdade que as instituições perpetuam quando operam a exclusão de discursos concorrentes e de outras agendas de reforma.

Segue que Bowe, Ball e Gold (1992) advertem que a mudança na administração central do ensino só é parcialmente explicada pela análise dos atos legislativos ou dos atores sociais. Isso ocorre porque fazem parte das estratégias de implementação das políticas educacionais expedientes que não requerem uma ação legislativa. Como Popkewitz (1997, p. 224225), entendem que na promulgação de regras administrativas por vezes são decisivos os trâmites do expediente interno das repartições centrais do ensino, a formação das equipes de direção executiva e mesmo os contextos das relações de grupo entre as diversas fronteiras institucionais. Sob esse aspecto, tanto se indica que há disputa e conflitos entre grupos com poder político no momento de definir as finalidades da educação quanto se considera que os professores e demais profissionais exercem um papel ativo no processo de interpretação das políticas educacionais (cf. Bowe, Ball, Gold, 1992, p. 22). A proposição de que as políticas educacionais são produtos de múltiplas influências e agendas e que a sua formulação envolve intenções e negociações dentro do Estado e no interior do próprio processo de concepção das reformas do ensino representa um desafio também para a historiografia da educação. Assim, quer o modelo 
analítico pensado por Ball e seus colaboradores seja útil numa perspectiva diacrônica, quer não, a proposição geral sobre a variedade de intenções e disputas que influenciam o processo político merece ser levada em consideração num estudo histórico das políticas públicas de educação.

\section{Sobre as fontes e a história das políticas educacionais}

No modo como foi formulada, a abordagem do ciclo de políticas envolve uma diversidade de procedimentos de coletas de dados. Nessa ordem de preocupações, a pesquisa bibliográfica, a entrevista com formuladores de políticas e com demais profissionais comprometidos, a análise de textos e documentos oficiais, de dados estatísticos e de avaliação do desempenho do aluno, entrevista com autores de textos de políticas e com aqueles para os quais os textos foram escritos e a aplicação de testes e questionários são elementos significativos para a construção dos dados sobre políticas públicas. Fundamentalmente, trata-se de instrumentos para a identificação e observação de conflitos, das formas da negociação durante o processo de decisão, das restrições colocadas sobre as questões a serem discutidas e decididas e das estratégias empregadas nos diferentes momentos do ciclo de políticas (cf. Mainardes, 2006, p. 60).

No que tange à história das políticas públicas de educação, um programa de pesquisa assim organizado não é sequer razoável para períodos muito distantes do presente. Principalmente, as lacunas na documentação e a impossibilidade de entrevistar "formuladores" e "intérpretes" das políticas educacionais são inerentes aos estudos historiográficos. No entanto, mesmo para períodos mais recentes, há complicações para se obter uma série tão extensa e completa de fontes, ainda que a história oral e a pesquisa etnográfica de caráter histórico auxiliem num tal esforço. E não parece ser somente a dificuldade de encontrar os vestígios de interpretação e de apropriação das diretrizes das políticas públicas por parte dos professores e demais profissionais da escola que oblitera o estudo do alcance e dos efeitos das reformas do ensino. Em função de novos conceitos a respeito da organização da sociedade e do Estado, a crítica das fontes tem mostrado problemática a utilização tanto dos dados estatísticos (Faria Filho, Neves, Caldeira, 2005; Gil, 2005) quanto dos impressos escolares (Catani, Vincentini, Lugli, 2002; Carvalho, 1998; Biccas, 2001; Bittencourt, 1996).

Assim, para a história das políticas públicas também interessam as fontes que traduzem o registro da sua geração e lhes dão materialidade. Um breve estudo de Sanfelice (2004) mostra, inclusive, que, no caso das políticas educacionais, a história da educação tem encontrado amplo campo para o levantamento de fontes documentais. Sobretudo são enfatizadas as fontes legislativas. De acordo com Sanfelice "desde as constituições, passando-se pelos decretos, até a legislação complementar, regulamentadora, tudo tem sido utilizado" (p. 100). Nesse estudo, também os diários do Congresso Nacional e do Senado Federal, os discursos e as 
intervenções dos deputados e senadores, na tramitação da legislação, aparecem como ricas fontes de pesquisa. Segue que o estudo das emendas populares, as emendas oferecidas em plenário, atas e jornais de Assembleias Constituintes, projetos derrotados e substitutivos quase sempre revelam muito mais do que a lei materializada (cf. Sanfelice, 2004). Ainda no âmbito do Estado, Faria Filho (2000) avalia que nos acervos e arquivos do aparelho estatal há uma forte presença de fontes escritas e outras resultantes de inovações tecnológicas, tais como fontes sonoras, de imagens e digitais, disponíveis ao investigador interessado.

Contudo, a historiografia reúne fontes produzidas por instituições que marcam forte presença na definição das políticas públicas sem, no entanto, pertencerem ao Estado. São os acordos, tratados, convênios, cooperação, recomendações, estudos e declarações promovidos pelo que Bowe, Ball e Gold (1992) denominam agências multilaterais, como o Banco Mundial, a OCDE, a Unesco e o FMI. Geralmente, trata-se de fontes que mostram, em alguma medida, o comprometimento do governo com políticas internacionais de financiamento das políticas públicas. Outro exemplo nesse sentido são as fontes geradas por instituições de variada natureza, mas que, por representarem interesses da sociedade civil, podem subsidiar as decisões de governo a respeito das políticas educacionais. Sanfelice (2004, p. 102) enumera uma grande quantidade delas, dando uma ideia da grandeza que é a malha na qual se tece a política educacional:

Como exemplo cito os programas de partidos políticos e enorme material diversificado que traduzem os interesses da Confederação Nacional da Indústria (CNI), da Confederação Nacional dos Bispos do Brasil (CNBB), do Conselho Nacional de Instituições da Educação Católica (Coniec), da Confederação Interestadual das Escolas Particulares (Fiep), da Confederação Nacional dos Estabelecimentos de Ensino (Confenen), da Central Única dos Trabalhadores (CUT), da Força Sindical, da Confederação Nacional dos Trabalhadores em Educação (CNTE), da Confederação Nacional dos Trabalhadores em Estabelecimentos de Ensino (Contee), e associações tais como: Educadores da América Latina e do Caribe (Aelac), Nacional de Educação (Ande), dos Docentes de Instituições do Ensino Superior (Andes-SN), Brasileira das Mantenedoras de Ensino Superior (Abmes), Brasileira de educadores de Deficientes Visuais (Abredev) etc.

Dessa mesma forma, estariam ainda as fontes resultantes dos procedimentos decorrentes da Federação das Universidades Brasileiras (Fasubra), da União Nacional dos Estudantes (UNE), da União Brasileira dos Estudantes Secundaristas (Ubes), da União Nacional dos Dirigentes Municipais de Educação (Undime), do Serviço Social da Indústria (Sesi), da Sociedade Brasileira para o Progresso da Ciência (SBPC), do Conselho de Reitores das Universidades Brasileiras (Crub) e muitas outras.

Embora a grandeza da malha na qual se tece a política educacional seja uma questão, o problema das fontes se apresenta marcante quanto ao tratamento, ao trabalho de crítica documental. Afinal, perante tamanha diversidade, a partir de quais elementos podem ser examinadas as políticas públicas de maneira rigorosa? Qualquer resposta sensata a esta indagação necessariamente passará por uma discussão acerca das metodologias e dos procedimentos da pesquisa historiográfica. Mesmo sem um 
exame preciso dos métodos utilizados atualmente pelos historiadores é possível organizar em parâmetros algumas proposições. Nesse sentido, a já famosa advertência de Dominique Julia (2001, p. 19) de que "os textos normativos devem sempre nos reenviar às práticas" é, seguramente, um desses parâmetros. Ainda que as normas que regem as escolas e os colégios sejam mais fáceis de atingir que as realidades dessas instituições, importa perguntar-se tanto sobre a genealogia desses textos quanto acerca das resistências e contradições que atravessam a aplicação de suas ambições (p. 21-23). Sobretudo nesse âmbito de preocupações, o estudo das políticas públicas implica "perceber concretamente a distância entre a realidade e a ambição inicial e a norma prescrita" (p. 36).

Tendo em conta "o jogo de representações sobre o que é a escola e como deve atuar", Diana Vidal (2005, p. 61) previne que, percebidas como práticas, as representações de escola e de seus sujeitos "confrontam-se com a materialidade do mundo na composição de corporeidades". Sob essa perspectiva, outro parâmetro de abordagem das políticas públicas diz respeito ao enfoque das representações que se produzem nas situações concretas do fazer cotidiano. Fundamentada em Certeau e Chartier, Vidal (p. 62) explica que os saberes técnicos e as reformas educativas são sempre gestados a partir de uma luta de representações. Sua atenção com o que essa luta revela acerca dos vários significados sociais da escola e sobre as práticas escolares coloca em questão que representações de escola e de seus agentes, praticadas pelos diferentes grupos sociais, estão em litígio quando se elaboram, se impõem e se resistem às reformas educativas (p. 64). É uma contribuição para o estudo das políticas públicas, na medida em que considera as representações sociais sobre a escola como "matrizes de práticas construtoras do próprio mundo social" (p. 63).

Um terceiro parâmetro para a investigação das políticas públicas de educação numa perspectiva histórica diz respeito diretamente ao que se considera ser uma história das políticas educacionais. Sanfelice (2004, p. 103) não tem nenhuma dúvida de que não se trata de outra coisa senão da história política. De fato, não há mesmo razões para censurar tal definição. Ocorre que esse âmbito dos estudos históricos tem renovado suas preocupações e as suas problemáticas de pesquisa muito na esteira das perspectivas abertas pela nova história cultural. Atualmente, a história política não é forçosamente uma história factual, psicológica, biográfica ou ideológica. Conforme Julliard (1976) havia vislumbrado e hoje, entre outros, Remond (2003) e Sirinelli (1998) vêm praticando, as questões mais recentemente postas pela história política observam o estudo do poder e da sua repartição. Mais que os atos e pensamentos das lideranças políticas, nota-se o interesse pela busca das respostas que as instituições políticas constituem para continuar funcionando no contato com instâncias sociais de outro tipo. Sobretudo nessa direção, as contribuições de Foucault $(1987,2003)$ têm auxiliado a compreensão das estratégias de governo para definir o que deve ou não ser referido ao Estado, o que é público e o que é privado, o que é estatal e o que não é estatal.

Por outro lado, a história cultural da política renovou a abordagem das relações entre as instituições políticas e a distribuição do poder. 
Principalmente nas perspectivas de análise de Sirinelli (1998) e Prost (1998), trata-se de uma abordagem que contribui para delinear as relações de diferentes práticas sociais com os poderes em circulação nas instituições políticas da sociedade. Nesse aspecto, a historiografia tem apresentado estudos que mostram, de um modo reiterado, as possibilidades de investigação das práticas culturais por meio das tecnologias de poder, das estratégias e das táticas produzidas para a sua legitimação (Vidal, 2005; Gomes, 1999; Veiga, 2003).

Com argúcia, Peter Burke (2005, p. 163) observou que a recente preferência pela nova história cultural estabeleceu avanços na pesquisa histórica, cuja vigência, embora incerta no futuro, já demonstrou as fraquezas dos métodos empiricistas ou positivistas. Segundo sua compreensão, vários deles "não eram suficientemente sensíveis ao simbolismo", outros muitos tratavam os documentos históricos como transparentes, "dando pouca ou nenhuma atenção à sua retórica" além de "descartarem certas ações humanas". Em muitos sentidos, Burke tem razão quando afirma que "qualquer que seja o futuro dos estudos históricos, não deve haver um retorno a esse tipo de compreensão", sendo mesmo necessário fazer todo o possível para que não se percam os ganhos recentes da percepção histórica, resultados da virada cultural. Nesse caso, também a história da educação mostra-se um veio propício para um trabalho de reinterpretação e reavaliação contínua do que se administra, se reforma ou se renova no ensino mediante uma ação de governo.

\section{Em torno da cultura escolar como objeto histórico}

Uma forma inicial de discutir as políticas educacionais no âmbito da história cultural da educação é examinar a ideia de cultura escolar como objeto histórico. Propondo-se a analisar historicamente a cultura escolar, Julia (2001) enfatizou o estudo das práticas escolares e do funcionamento interno das escolas. Sua conferência no International Standing Conference for the History of Education (Ische), publicada na Paedagogica Historica e, em português, na Revista Brasileira de História da Educação, é um convite aos historiadores da educação a se interrogarem sobre as práticas escolares cotidianas. No cerne da definição de cultura escolar, enunciada por Julia (2001, p. 10-11), está a relação entre as noções de norma e de prática:

Para ser breve, poder-se-ia descrever a cultura escolar como um conjunto de normas que definem conhecimentos a ensinar e condutas a inculcar, e um conjunto de práticas que permitem a transmissão desses conhecimentos e a incorporação desses comportamentos; normas e práticas coordenadas a finalidades que podem variar segundo as épocas. Normas e práticas não podem ser analisadas sem se levar em conta o corpo profissional dos agentes que são chamados a obedecer a essas ordens e, portanto, a utilizar dispositivos pedagógicos encarregados de facilitar sua aplicação, a saber, os professores primários e os demais professores. 
O que em geral era tratado de modo externalista pela história das ideias pedagógicas, das instituições educativas ou das populações escolares, foi então considerado sob uma perspectiva internalista, de acordo com uma história das disciplinas escolares (cf. Faria Filho et al., 2004, p. 144). Nesse sentido, Julia (2001, p. 15) adverte acerca da necessidade de recontextualizar as fontes das quais se dispõe, uma vez que "a grande inércia que percebemos em um nível global pode estar acompanhada de mudanças muito pequenas que insensivelmente transformam o interior do sistema".

Os estudos de André Chervel acerca da ortografia (Chervel, BlancheBenveniste, 1969), da gramática (Chervel, 1977), do ditado (Chervel, 1989) e da composição francesa (Chervel, 1999) nos séculos 19 e 20, bem como sua crítica aos esquemas explicativos que tinham a noção da escola como simples agente de transmissão de saberes elaborados fora dela, foram extremamente influentes nesse sentido. Tendo por base o arrazoado de que a escola produz uma cultura específica, singular e original, Chervel (1998, p. 190) repensa as consequências sociais e políticas da escolarização a partir da cultura que a escola lega à sociedade. Em relação ao estudo das políticas públicas de educação, as suas conclusões são principalmente relevantes em dois aspectos. Por um lado, a cultura escolar, em parte, traduz-se em resultados esperados pelos programas oficiais de ensino. Por outro, revela efeitos imprevistos, engendrados independentemente pelo sistema escolar. A Chervel (1990, p. 184) o sistema escolar parece produzir criações espontâneas e originais, que merecem um interesse todo particular. Muito em função disso, sua atenção recai sobre os fatos próprios e restritos à escola e que não puderam em momento algum ser exatamente referidos às ciências, às artes ou a quaisquer outras práticas culturais (cf. Chervel, 1998, p. 192).

Contudo, a noção de que a categoria cultura escolar pode ser útil para pensar os resultados das políticas educacionais foi explorada de forma mais pormenorizada por Viñao Frago (1995, 2000, 2001). Fundamentalmente, ele entendeu que, longe de sugerir uma construção ou estrutura única, a cultura escolar é múltipla e diversa. A Viñao Frago (2001, p. 33-34) pareceu mais frutífero e interessante falar, no plural, em culturas escolares tanto por compreender cada escola como um caso quanto por considerar a especificidade cultural de cada centro docente, de cada nível educativo e de cada um dos grupos de atores que intervêm na vida cotidiana dos estabelecimentos de ensino. Desde uma perspectiva histórica, observou que as políticas educacionais incidem sobre modos de fazer e pensar já estáveis e persistentes nas instituições escolares. Ainda que reconheça haver reformas sem mudanças e mudanças sem reformas, Viñao Frago mostrou ter um particular interesse nas mudanças escolares provocadas pelas reformas educativas (p. 46). Sob sua ótica, contudo, a análise privilegia o caráter contextual circunstancial e às vezes imprevisível da tarefa educativa, assim como a complexidade dos sistemas educativos e a conseguinte impossibilidade de ter em conta todos os fatores ou elementos em jogo (p. 39-40).

Para pensar as circunstâncias e os fatores das mudanças educativas em termos políticos, Viñao Frago propõe duas adequações significativas à 
noção de cultura escolar. Ele sugere que há uma cultura política da escola que separa reformadores e gestores de professores. Sob esse aspecto, a ideia básica de Viñao Frago (2001, p. 35) é de que "a posição e pontos de vista diferentes de reformadores e professores determina o relativo fracasso das reformas educativas". Nessa forma de análise, as diferenças fundamentais entre as prioridades e preocupações de gestores e docentes implicam diferenças culturais que opõem um conjunto de crenças, mentalidades e práticas de interação e trabalho adquiridas, arraigadas e transmitidas, não sem modificações, de uma geração para outra de docentes aos procedimentos burocrático-formais das políticas educacionais. Porém, Viñao Frago distingue, na esteira de Escolano, três culturas da escola (p. 42). Assim, adverte que na escola coexistem uma cultura do conhecimento experto, gerada no mundo acadêmico; uma cultura político-institucional, produzida no entorno administrativo-burocrático dos serviços educativos; e uma cultura empírico-prática, elaborada pelos professores na prática da sua profissão, que constitui a "memória corporativa da docência". As tensões entre expertos, administradores e docentes são cruciais para explicar as relações que as políticas de reforma mantêm com as culturas escolares:

[Las instituciones de enseñanza] actúan dentro de uno marco legal y de una política determinada, que tiene su propria cultura; una cultura gestionada por reformadores, gestores y supervisores com su propria y específica cultura de la escuela - concepción o forma de verla - , y en interacción com una ciencia o ciencias de la educación - pedagogía, psicopedagogía y sociología de la educación fundamentalmente - que influye en las reformas educativas, que condiciona la cultura escolar y cuyos protagonistas - pedagogos, psicólogos, sociólogos - se erigen en detentadores del saber experto y científico en el ámbito educativo. Esta doble interacción, y enfrentamiento, de la cultura de los professores y maestros com las culturas de los reformadores y gestores y de los expertos o científicos de la educación - siempre tentados, cuando las circunstancias políticas los permiten, a convertirse en reformadores - es la que explica, en buena parte, el fracasso de las reformas educativas. (Viñao Frago, 2001, p. 34-35).

$\mathrm{Na}$ acepção deste autor, a categoria cultura escolar aparece, então, como um elemento de resistência às mudanças nas escolas. Nesse sentido, a compreensão de Viñao acerca da cultura escolar é diversa das noções enunciadas por Julia (2001) e Chervel (1998), que recorreram ao conceito para externar suas crenças nas inovações pedagógicas. Portanto, "cultura escolar" é uma categoria de análise que possui significados concorrentes. Faria Filho et al. (2004) abordaram de forma sistemática a especificidade com que o termo é empregado em cada autor. No que concerne ao estudo sobre professores, notam que Viñao Frago valoriza a diferença entre saber docente e técnico, enquanto Chervel e Julia "veem o professor como aquele que põe em funcionamento os dispositivos escolares de maneira criativa respeitando as normas estabelecidas". Quanto às mudanças, avaliam que Viñao reafirma a pouca permeabilidade da cultura escolar às transformações, enquanto Julia e Chervel acolhem 
as rupturas em pequena escala, preocupando-se com as inflexões desse termo. A respeito do impacto da escolarização sobre a sociedade, Faria Filho et al. (2004) compreendem o alcance teórico da noção de cultura escolar a partir do argumento de Viñao Frago sobre a depreciação social do analfabeto e mediante o modo como Chervel percebe os estigmas sociais imputados àqueles que não escrevem corretamente. Nesse mesmo âmbito, Julia remete à preocupação com a schooled society (cf. Faria Filho et al., 2004, p. 149).

A discussão sobre a cultura escolar tem propiciado um repertório analítico que abrange desde os impressos pedagógicos até as práticas da leitura e da escrita, passando, inclusive, pelo estudo das disciplinas escolares, dos métodos de ensino e do tempo e espaço escolares. Tem sido registrada uma tendência crescente a se pensar sobre a cultura escolar como uma categoria para estudar o processo de escolarização que se dá em um determinado momento (cf. Faria Filho et al., 2004, p. 153; Vidal, 2005). Do ponto de vista das políticas educacionais, as questões gerais levantadas nessa tendência da discussão parecem interligadas, com pressupostos a respeito da organização administrativa e pedagógica do ensino (Viñao Frago, 2001; Souza, 1998; Faria Filho, 2000). Dedica-se cada vez mais atenção à cultura escolar também no tocante ao governo e à administração do sistema educativo e escolar, à sua estruturação ou financiamento, ao currículo e ao professorado. Nessas instâncias de abordagem, Vidal (2005, p. 31-32, p. 37-45) identificou tanto as raízes do que chamou de invariante estrutural da escola quanto os indícios da capacidade produtora ou criadora de configurações cognitivas originais que a escola mostra ter. De ambos os modos, como categoria de análise, a cultura escolar acrescenta perspectivas de abordagem significativas ao estudo histórico e sociológico das políticas educativas.

\section{A respeito das instituições escolares}

As mais recentes investigações acerca das formas de escolarização têm mostrado que a escola produziu diferentes efeitos de socialização ao longo do tempo. Guy Vincent (1980) estudou alguns desses efeitos pesquisando a emersão da escola como um lugar específico e separado das outras práticas sociais. Preocupado em compreender as permanências na organização da escola, empregou o termo forma escolar para pesquisar o que faz a unidade de uma configuração histórica particular. Conforme explicou Diana Vidal (2005, p. 39), a categoria forma escolar foi gestada tendo em mira "a disseminação de saberes elementares e as relações entre mestre e aluno, em um espaço e tempo normatizados". Vincent (1980) e colaboradores (Vincent, Lahire, Thin, 2001) ocuparam-se do estudo do papel das regras na aprendizagem e da organização racional do espaço e do tempo da escola primária. Significativamente, eles fornecem explicações para o fato de o modo escolar de socialização se estender e se generalizar a ponto de se tornar o modo de socialização dominante 
das atuais formações sociais (cf. Vincent, Lahire, Thin, 2001, p. 38). A lógica escritural, a impessoalidade das condutas, as classificações e as temporalidades que a escola impõe à infância são compreendidas como práticas que não só perduram solidamente nas instituições educativas, mas também organizam as relações sociais contemporâneas (p. 45-46).

Também para uma história das permanências na organização da escola, David Tyack e Larry Cuban (1999) cunharam a expressão "gramática da escola" (grammar of schooling). Como Vincent, propuseram-se a analisar a instituição escolar com base nas invariantes, fixando suas atenções nas normas e estruturas de funcionamento consagradas. Igualmente, Tyack e Cuban (1999, p. 85) encontraram as formas estáveis da organização escolar da educação no formato das salas de aula, na maneira como a escola divide o espaço e o tempo, classifica o aluno e os distribui por classes e separa o conhecimento por matérias. A expressão gramática escolar entrou em suas análises para explicar que, em sociedades profundamente escolarizadas, como a estadunidense, há a tendência de se consolidar uma noção do que seja a escola de verdade e de se recusar tudo que se afastasse do modelo, impondo obstáculos às mudanças. Nessa perspectiva, as continuidades nas práticas de organização escolar são buscadas em função da abordagem das estratégias de estruturação do sistema educativo. Particularmente na ótica de Viñao Frago (2001, p. 29), uma abordagem desse tipo permite dar uma definição e fazer uma caracterização conjunta de "teorías, ideas, principios, normas, pautas, rituales, inercias, hábitos y practicas sedimentadas a lo largo del tiempo en forma de tradiciones, regularidades y regras de juego no puestas en entredicho y compartidas por sus actores en el senso de las instituciones educativas".

A utilização de categorias como "forma escolar", "gramática da escola" e mesmo "cultura escolar" auxilia a compreensão dos estabelecimentos escolares como instituições. Fundamentalmente, essas categorias de análise podem ajudar a entender as práticas culturais, sociais e políticas, que criam ou transformam as diferentes partes da instituição escolar. De fato, a organização das condições materiais da educação (Souza, 1998; Faria Filho, 2000; Vidal, 2001), bem como dos dispositivos de controle doutrinário do magistério (Carvalho, 2002; Biccas, 2001) e da autoridade e hierarquia administrativa das escolas (Torres, 2005), já possuem estudos a partir dessa abordagem. No conjunto, tais estudos trouxeram uma efetiva contribuição para o entendimento histórico das propriedades das instituições escolares e de seu funcionamento. Oferecem um ângulo de compreensão dos estabelecimentos de ensino a partir da análise das convicções culturais que geraram ou modificaram as escolas. Conforme coloca Molero Pintado (2000, p. 227):

Las convicciones culturales que genera la escuela terminan proyectado su influencia sobre los aspectos más íntimos del aula de clase y de la vida del centro. Es éste un capítulo menos conocido, menos divulgado, pero que en el momento presente há logrado una gran audiencia entre el amplio campo de la investigación histórica. La configuración de los modelos estructurales y organizativos de la escuela sólo és posible interpretala desde esta perspectiva. 
A capacidade produtora ou criadora de configurações cognitivas originais que a escola apresenta tem sido pensada de forma inversa. Os estudos de Chervel (1990, p. 184; 1998, p. 190) acerca das disciplinas escolares mostram que a cultura legada pela escola à sociedade traz efeitos imprevisíveis, engendrados pelo próprio sistema escolar. Segundo Vidal (2005, p. 27-28), o exemplo típico disso foi o modo como, na França, "o difícil aprendizado da ortografia deu origem à elaboração de uma teoria das funções, puramente escolar e operatória, constituída no intramuros da escola por mestres em atividade, que respondia às urgências do ensino". Nessa perspectiva, o enfoque das mudanças pretendidas pelas iniciativas de reforma educativa ou por uma política escolar foi alvo de críticas e tachado de redutor, preferindo-se tratar câmbios impetrados imperceptivelmente nas formas de organização do ensino.

Nessa linha, Antoine Prost propõe tornar problemática a relação entre mudança e reforma quando do estudo dos aspectos estruturais da escola. De acordo com suas conclusões, as alterações nas práticas escolares não resultam necessariamente de reformas, podendo se efetuar por consenso tácito, implícito por uma série de ajustamentos dos conteúdos a situações pedagógicas específicas (cf. Prost, 1996, p. 15). Diana Vidal ([s.d.]) também tem decomposto as relações entre escola, reforma educacional e mudança. Ela salienta que as mudanças se operam não apenas em função das premissas pedagógicas, "mas espelham as tensões que se estabelecem na sociedade entre as várias instituições sociais" (p. 18). Tanto quanto Stephen Ball, ainda que por meios diferentes, Prost (1996, p. 23) e Vidal ([s.d.], p. 18) percebem as interferências e controvérsias do debate público como instâncias significativas da elaboração política das reformas educativas. Sob essa perspectiva, mais que as normas, os materiais ou os métodos escolares, estudam-se as suas apropriações por professores, alunos e responsáveis administrativos.

Chapoulie e Briand (1994) também estão entre os que insistem sobre o caráter analítico da distinção entre ambos os conjuntos de efeitos das políticas educacionais. Todavia, suas preocupações centram-se no papel das autoridades administrativas capazes de traduzir decisões políticas em ações institucionais. O interesse das análises de Chapoulie e Brian está nos agentes intermediários dos domínios da decisão política e da ação no interior da instituição escolar e no modo como contribuem para "transformar certos 'problemas' que o funcionamento da instituição engendra em questões publicamente debatidas e, portanto, submetidas a um trabalho de elaboração política" (p. 28). Nesse caso, a utilização da noção de forma de escolarização tem levado a uma visão de conjunto sobre os processos de criações institucionais no campo educativo que tanto se refere aos seus princípios de definição e legitimidade quanto diz respeito às condições de realização institucional das mudanças. Para aquilo que Chapoulie e Briand chamam de política escolar (p. 32-33), verifica-se que o termo auxilia a abordagem da transformação do status conferido a um problema escolar de acordo com a diversidade dos atores, já que tem 
em vista que a contribuição dos adversários de uma criação ou inovação nem sempre é menor que aquela dos colaboradores.

As contribuições de Chapoulie e Briand para a análise das políticas educacionais são maiores em outro âmbito de entendimento. Um dos pontos altos da discussão deles em torno dos processos de escolarização é a compreensão de que a instituição escolar não contribui somente com a realização da política escolar por meio da forma como reinterpreta e coloca em ação as decisões ou pressões advindas do domínio público. Segundo apontam Chapoulie, (1980), a instituição escolar, mediante a atuação de seus agentes, "constitui certos 'fatos' em problemas escolares ou sociais, em torno dos quais desenvolvem-se controvérsias públicas". Em razão disso, defende-se, sob essa perspectiva, que a análise da política educacional não pode examinar de forma isolada os dois termos que a definem: a política e a instituição (Chapoulie, Briand, Peretz, 1980, p. 28-29; Desaulniers, 1992, p. 99). O que é fundamental é compreender as interações existentes entre ambas as ordens de fatos.

Outras abordagens sobre as instituições escolares têm se mostrado possíveis e significativas para a historiografia da educação. António Nóvoa, por exemplo, propôs-se analisar a escola enquanto organização, ressaltando não apenas a história das ideias sobre educação ao longo das últimas cinco décadas mas, também, o emprego de categorias como cultura de escola e cultura organizacional da escola. Seu estudo sobre as organizações escolares é aberto ao modelo político de Stephen Ball em razão da série de conceitos que introduz na análise das organizações escolares. Segundo Nóvoa (1995, p. 25), as noções de poder, disputa ideológica, conflito, interesse, controle e regulação enriquece o estudo da estrutura formal e das interações que se produzem na escola entre grupos com interesses distintos. Outro modelo de análise que pauta o estudo de Nóvoa acerca da escola enquanto organização é o simbólico. Esse modelo, que vem da sociologia das organizações escolares, põe a tônica no significado que os diversos atores dão aos acontecimentos e no caráter incerto e imprevisível dos processos organizacionais mais decisivos (cf. Borrel Felip, 1989). Sob essa perspectiva, António Nóvoa (1995, p. 25-32) compreende que para uma análise das instituições escolares é central o estudo tanto das estruturas funcionais da escola (física, administrativa e social) quanto do que ele chama de zonas de invisibilidade (bases conceituais e pressupostos invisíveis) e de visibilidade (manifestações verbais, conceituais, visuais, simbólicas e comportamentais).

Outra abordagem institucional da escola é feita por Justino Magalhães (1998) a partir de um referencial historiográfico. Ele percebe o modelo escolar como uma "complexidade espaço-temporal, pedagógica e organizacional, onde se relacionam elementos materiais e humanos mediante papéis e representações diferenciados, entretecendo e projetando através de expectativas institucionais" (p. 61). Sob essa perspectiva, a história das instituições educativas lhe parece ser um modelo epistêmico para a construção de um sentido histórico das instâncias centrais dos sistemas educativos modernos e contemporâneos. Magalhães pensa esse modelo 
enquanto um domínio de conhecimento adequado para realizar "uma síntese multidimensional capaz de decodificar um itinerário pedagógico, uma identidade histórica, uma realidade em evolução, um projeto pedagógico" (p. 61). Assim, defende que são várias as dimensões de estudo necessárias à história das instituições escolares. Desde a dimensão material do empreendimento educativo até a ação educativa dos docentes, passando pela apropriação que os alunos e a sociedade fazem da escola, o estudo da criação e das transformações da organização da instituição escolar envolve a articulação de uma série de eixos de aproximação à dinâmica histórica do modelo escolar de ensino (p. 63). Não por outra razão, a história da escola é definida como uma triangulação entre a materialidade das práticas, a representação discursiva e a apropriação de atos de direção e decisão (p. 64).

De muitos modos, portanto, a história das instituições escolares registra o que reflete o papel do Estado junto ao desenvolvimento da escola. Seja como investigação das invariantes estruturais da escola ou, inversamente, da inventividade das práticas escolares, seja para elaborar uma visão de conjunto sobre as criações institucionais no campo educativo, o estudo da organização escolar constituiu-se num nível essencial para a abordagem dos fenômenos educativos. Segundo uma análise perspicaz da historiografia da educação, a história das instituições escolares acaba por traduzir-se em desafios metodológicos para a pesquisa em história da educação na medida em que coloca questões de produção, circulação e apropriação culturais (Nunes, Carvalho, 1993, p. 47-49).

\section{As políticas públicas de educação enquanto questão historiográfica}

As pesquisas sobre instituições de ensino, os estudos acerca do ciclo de políticas públicas, as investigações a respeito da sociologia política das reformas educativas, as observações a propósito da cultura escolar contribuem para ressaltar tanto a variedade quanto a força das interações entre todas essas perspectivas de abordagem das políticas educacionais. Portanto, é útil tratá-las como complementares uma à outra, tendo em vista que cada uma delas salienta algumas características da ação de governo sobre o ensino em detrimento de outras. As pesquisas sobre as instituições educativas parecem mais pertinentes à compreensão das dinâmicas de mudança das formas de escolarização e um estudo no âmbito da cultura escolar mais adequado ao entendimento tanto das inovações de pequena abrangência quanto das invariantes estruturais do ensino e da escola. Contudo, a sociologia política das reformas educativas é tão mais afeita a estudos das relações estruturadas entre diferentes instituições educativas quanto a abordagem do ciclo de políticas o é em relação ao entendimento dos processos de formulação e análise da agenda (agenda setting) de reforma.

O que, de fato, essas perspectivas de abordagem sugerem à história da educação são novas questões ou, em vez disso, novas respostas a 
perguntas bastante conhecidas. Sobretudo trabalhando com diferentes durações de tempo, apoderando-se de processos mais globais de escolarização, procurando nas práticas cotidianas o entendimento do conjunto de fazeres ativos no interior da escola e inventariando estratégias, a história da educação tem precisado discutir as formas pelas quais as decisões de indivíduos ou pequenos grupos exerceram influência sobre o desenvolvimento social da educação. A princípio, põe-se a questão das condições sob as quais se formaram as representações de escola e os discursos sobre educação no âmbito político das ações de Estado (Nunes, Carvalho, 1993, p. 41-42). Há também a questão da acentuada distância ou incongruência das práticas escolares em relação aos saberes técnicos ou às leis e reformas educativas (Vidal, 2005, p. 63; Prost, 1996, p. 16-17). Não por outra razão, uma diferente questão suscitada pela historiografia da educação diz respeito às relações entre macroanálise e micro-história. Significativamente, considerar as políticas de organização escolar como um nível da abordagem histórica das mudanças educacionais tem sido um recurso útil para compreender a construção de projetos educativos entre o nível macro das reformas estruturais do sistema educativo e o nível micro da aplicação de novos métodos e técnicas pedagógicas na sala de aula (cf. Nóvoa, 1995, p. 40).

A propósito da conclusão, vale a pena citar o que Clarice Nunes (1992, p. 152) escreveu sobre a recriação de um objeto de pesquisa:

\begin{abstract}
A recriação de um objeto no processo de pesquisa é mais complexa do que parece à primeira vista, antes de mais nada, porque é um problema de concepção que enfrenta os mais diversos obstáculos: o da cristalização das matrizes interpretativas e de sua necessária crítica, o das fontes de pesquisa, o da reconstrução das categorias analíticas, o da sua narração. O espaço da criação de um novo objeto é menos um campo delimitado com precisão, embora estejamos a todo momento procurando defini-lo, e mais a tessitura de uma estratégia de desvio que permita elaborar ângulos múltiplos de construção do próprio objeto [grifos no original].
\end{abstract}

Nessa perspectiva, tratar do que o governo faz, ou deixa de fazer, em educação como política pública talvez seja mais um esforço lógico e político de distinguir uma questão de pesquisa do que, propriamente, o exemplo mais claro de recriação de um objeto de estudo. No entanto, diante da grave situação do ensino público atual, entender a história da ação de governo na educação é, sobretudo, aceitar o desafio de lembrar aquilo que, nas palavras de Hobsbawm (1995, p. 107), os "colegas-cidadãos desejam esquecer".

\title{
Referências bibliográficas
}

BALL, Stephen J. What is policy? Texts, trajectoires and toolboxes.

Discourse, London, v. 13, n. 2, p. 10-17, 1993. 
BALL, Stephen J. Education reform: a critical and post-structural approach. Buckingham: Open University Press, 1994.

. Big policies/small word: an introduction to international perspectives in education policy. Comparative Education, Penn State, v. 34, n. 2, p. 119-130, 1998.

Diretrizes políticas globais e relações políticas locais em educação. Currículo sem Fronteiras, Porto Alegre, v. 1, n. 2, p. 27-43, 2001.

BICCAS, Maurilane de Sousa. O impresso como estratégia de formação de professores (as) e conformação do campo pedagógico em Minas Gerais: o caso da Revista do Ensino (1925-1940). 2001. Tese (Doutorado em Educação) - Universidade de São Paulo (USP), São Paulo, 2001.

BITTENCOURT, Circe M. F. Práticas de leitura em livros didáticos. Revista da Faculdade de Educação, São Paulo, v. 22, n. 1, p. 89-110, jan./jun. 1996.

BORREL FELIP, Nuria. Organización escolar: teoría sobre las currientes científicas. Barcelona: Editorial Humanitas, 1989.

BOURDIEU, Pierre; PASSERON, Jean Claude. A reprodução. Rio de Janeiro: Francisco Alves, 1975.

BOWE, R.; BALL, Stephen J.; GOLD, A. Reforming education and changing schools: case studies in policy sociology. London: Routledge, 1992.

BURKE, Peter. A revolução francesa da historiografia: a Escola dos Annales 1929-1989. São Paulo: Ed. Unesp, 1991.

. O que é história cultural. Rio de Janeiro: Zahar, 2005.

CARVALHO, Marta Maria Chagas de. Pedagogia da Escola Nova, produção da natureza infantil e controle doutrinário da escola. In: FREITAS, Marcos Cezar de; KUHLMANN JÚNIOR, Moysés (Org.). Os intelectuais na história da infância. São Paulo: Cortez, 2002. p. 373-408.

Por uma história cultural dos saberes pedagógicos. In: SOUSA, Cynthia Pereira de; CATANI, Denice B. Práticas educativas, culturas escolares, profissão docente. São Paulo: Escrituras, 1998. p. 31-40.

CATANI, Denice B.; VINCENTINI, Paula Perin; LUGLI, Rosário S. Genta. A profissionalização e as práticas de organização dos professores: estudos 
a partir da imprensa periódica educacional. In: CATANI, Denice B.;

BASTOS, Maria Helena (Orgs.). Educação em revista: a imprensa periódica e a história da educação. São Paulo: Escrituras Editora, 2002, p. 47-76.

CHAPOULIE, Jean-Michel; BRIAND, Jean-Pierre. A instituição escolar e a escolarização: uma visão de conjunto. Educação \& Sociedade, Campinas, n. 47, p. 11-60, abr. 1994.

CHAPOULIE, Jean-Michel; BRIAND, Jean-Pierre; PERETZ, Henri. L'évolution de la scolarisation pos-obligatoire: un schéma d'analyse. Revue Reflexions Historiques, v. 7, p. 7-27, 1980.

CHARTIER, Roger. A história cultural: entre práticas e representações. Lisboa: Difel, 1990.

CHERVEL, André. Histoire de la grammaire scolaire. Paris: Payot, 1977. . La dictée: les français et l'orthographe (1873-1987). Paris: INRP, Calmann-Lévy, 1989.

. História das disciplinas escolares: reflexões sobre um campo de pesquisa. Teoria e Educação, Porto Alegre, v. 2, p. 177-229, 1990. . La culture scolaire: une approche historique. Paris: Belin, 1998. . La composition française au XIXe. siècle dans le principaux concours et examens de l'agrégation au baccalauréat. Paris: INRP, Vuibert, 1999.

CHERVEL, André; BLANCHE-BENVENISTE, Claire. L'orthographe. Paris: Maspero, 1969.

CUIN, Charles-Henry; GRESLE, François. História da sociologia.

São Paulo: Ensaio, 1994.

DESAULNIERS, Julieta B. Ramos. Instituição e evolução da escolarização. Teoria e Educação, Porto Alegre, n. 6, p. 97-104, 1992.

EDWARDS, R. et al. Rhetoric and educational discourse: persuasive texts? London: Routledge Falmer, 2004.

FARIA FILHO, Luciano Mendes de. Dos pardieiros aos palácios: cultura escolar e cultura urbana em Belo Horizonte na Primeira República.

Passo Fundo, UFP, 2000.

FARIA FILHO, Luciano Mendes de; NEVES, Leonardo Santos;

CALDEIRAS, Sandra Maria. A estatística educacional e instrução 
pública no Brasil: aproximações. In: CANDEIAS, Antônio. Modernidade, educação e estatísticas na Ibero-América dos séculos XIX e XX: estudos sobre Portugal, Brasil e Galiza. Lisboa: Educa, 2005. p. 219-228.

FARIA FILHO, Luciano Mendes de et al. A cultura escolar como categoria de análise e como campo de investigação na história da educação brasileira. Educação e Pesquisa, São Paulo, v. 30, n. 1, p. 139-160, jan./abr. 2004.

FOUCAULT, Michel. A "governamentalidade": curso do Collège de France, ano 1977-1978. In: . Ditos e escritos, v. IV: Estratégia poder-saber. São Paulo: Forense Universitária, 2003. p. 281-305. 1987. . Vigiar e punir: nascimento da prisão. Petrópolis: Vozes,

GIL, Natália. A educação nos censos populacionais brasileiros (1872-1960). In: CANDEIAS, Antônio. Modernidade, educação e estatísticas na Ibero-América dos séculos XIX e XX: estudos sobre Portugal, Brasil e Galiza. Lisboa: Educa, 2005. p. 273-287.

GOMES, Angela de Castro. Essa gente do Rio... modernismo e nacionalismo. Rio de Janeiro: FGV, 1999.

HOBSBAWM, Eric. Era dos extremos: o breve século XX - 1914-1991. São Paulo: Companhia das Letras, 1995.

JULIA, Dominique. A cultura escolar como objeto histórico. Revista Brasileira de História da Educação, Campinas, n. 1, p. 9-44, 2001.

JULLIARD, Jacques. A política. In: LE GOFF, Jacques; NORA, Pierre. História; novas abordagens. Rio de janeiro: Francisco Alves, 1976. p. 180-195.

MAGALHÃES, Justino. Um apontamento metodológico sobre a história das instituições educativas. In: SOUZA, Cynthia Pereira de; CATANI, Denice Barbara (Org.). Práticas educativas, culturas escolares, profissão docente. São Paulo: Escrituras, 1998. p. 51-69.

MAINARDES, Jefferson. Abordagem do ciclo de políticas: uma contribuição para a análise de políticas educacionais. Educação e Sociedade. Campinas, v. 27, n. 94, p. 47-69, jan./abr. 2006.

MOLERO PINTADO, Antonio. En torno a la cultura escolar como objeto histórico. In: BERRIO, Julio Ruiz (Ed.). La cultura escolar de Europa: tendencias históricas emergentes. Madrid: Biblioteca Nueva, 2000. p. 223-228. 
NÓVOA, António. Para uma análise das instituições escolares. In:

NÓVOA, António (Org.). As organizações escolares em análise. Lisboa:

Dom Quixote, 1995. p. 13-43.

NUNES, Clarice. História da educação brasileira: novas abordagens de velhos objetos. Teoria e Educação, Porto Alegre, n. 6, p. 151-181, 1992.

NUNES, Clarice; CARVALHO, Marta M. Chagas de. Historiografia da educação e fontes. Cadernos ANPEd, Porto Alegre, n. 5, p. 7-64, set. 1993.

POPKEWITZ, Thomas S. Paradigm and ideology in educational research: the social functions of the intellectual. New York: The Falmer Press, 1984.

. Cultura, pedagogia, e poder. Teoria e Educação, Porto Alegre, n. 5, p. 91-107, 1992.

. La relación entre poder y conocimiento en la enseñanza y en la formación docente. Propuesta Educativa, Buenos Aires, n. 13, p. 30-43, 1994.

Reforma educacional: uma política sociológica - poder e conhecimento em educação. Porto Alegre: Artes Médicas, 1997.

História do currículo, regulação social e poder. In: SILVA, Tomaz Tadeu da (Org.). O sujeito da educação: estudos foucaultianos. 3. ed. Petrópolis: Vozes, 1999. p. 173-210.

PROST, Antoine. Comment faire l'histoire des réformes de l'enseignement? In: BELHOST, Bruno; GISPERT, Hélène; HULIN, Nicole. Les sciences au licée: un siècle de réformes des mathématiques et de la physique en France et à l'étranger. Paris: Vuibert, INPR, 1996. p. 15-25.

Social e cultural indissociavelmente. In: RIOUX, Jean Pierre; SIRINELLI, Jean François. Para uma história cultural. Lisboa: Editorial Estampa, 1998.

RÉMOND, René (Org.). Por uma história política. 2. ed. Rio de Janeiro: FGV, 2003.

ROBERTSON, R. Globalisation: time-space and homogeneityheterogeneity. In: FEATHERSTONE, M.; LASH, S.; ROBERTSON, R. (Ed.). Global modernities. London: Sage, 1995. p. 25-44. 
SANFELICE, José Luís. Fontes e história das políticas educacionais. In: LOMBARDI, José Claudinei; NASCIMENTO, Maria Isabel Moura (Org.). Fontes, história e historiografia da educação. Campinas: Autores Associados, 2004. p. 97-108.

SIRINELLI, Jean-François. De la demeure à l'agora: por une histoire culturelle du politique. Vingtième Siècle, Paris, n. 57, p. 121-131, jan./mar. 1998.

SOUZA, Celina. "Estado do campo" da pesquisa em políticas públicas no Brasil. Revista Brasileira de Ciências Sociais, São Paulo, v. 18, n. 51, p. 15-20, fev. 2003.

SOUZA, Rosa Fátima de. Templos de civilização: a implantação da escola primária graduada no Estado de São Paulo (1890-1910). São Paulo: Unesp, 1998.

TORRES, Leonor Lima. Cultura organizacional no contexto escolar: o regresso à escola como desafio na reconstrução de um modelo teórico. Ensaio, Rio de Janeiro, v. 13, n. 49, p. 435-451, out./dez. 2005.

TYACK, David; CUBAN, Larry. Tinkering toward utopia: a century of public school reform. Cambridge, Mass.: Harvard University Press, 1999.

VEIGA, Cynthia Greive. História política e história da educação. In: FONSECA, Thais Nívia de Lima; VEIGA, Cynthia Greive. História e historiografia da educação no Brasil. Belo Horizonte: Autêntica, 2003. p. 11-48.

VIDAL, Diana Gonçalves. O fracasso das reformas educacionais: um diagnóstico sob suspeita. [s.d.]. (Não publicado - 23 p).

.Culturas escolares: estudo sobre práticas de leitura e escrita na escola pública primária (Brasil e França, final do século XIX). Campinas: Autores Associados, 2005.

. O exercício disciplinado do olhar: livros, leituras e práticas de formação docente no Instituto de Educação do Distrito Federal (19321937). Bragança Paulista: EDUSF, 2001.

VIÑAO FRAGO, Antonio. Historia de la educación e historia cultural. Revista Brasileira de Educação, São Paulo, n. 0, p. 63-82, set./dez. 1995. . Culturas escolares, 2000. (Não publicado - 8 p.). 
VIÑAO FRAGO, Antonio. Fracasan las reformas educativas?

La respuesta de un historiador. In: SBHE. Educação no Brasil.

Campinas: Autores Associados, 2001. p. 21-52.

VINCENT, Guy. L'école primaire française. Lyon: Presses Universitaires de Lyon, 1980.

VINCENT, Guy; LAHIRE, B.; THIN, D. Sobre a história e a teoria da forma escolar. Educação em Revista, Belo Horizonte, p. 7-48, jun. 2001.

André Luiz Paulilo, doutor em Educação pela Universidade de São Paulo (USP), é professor da Universidade Municipal de São Caetano do Sul (USCS) onde coordena o Programa de Estudo e Ensino das Ciências Sociais (Proeecs).

paulilo@uscs.edu.br

Recebido em $1^{\circ}$ de fevereiro de 2010.

Aprovado em 16 de setembro de 2010. 